\title{
Adult dogs are capable of regulating calcium balance, with no adverse effects on health, when fed a high-calcium diet
}

\author{
Jonathan Stockman ${ }^{1}$, Phillip Watson ${ }^{1 *}$, Matthew Gilham ${ }^{1}$, David Allaway ${ }^{1}$, Jujhar Atwal ${ }^{1}$, \\ Richard Haydock ${ }^{1}$, Alison Colyer ${ }^{1}$, Helen Renfrew ${ }^{2}$ and Penelope J. Morris ${ }^{1}$ \\ ${ }^{1}$ WALTHAM Centre for Pet Nutrition, Waltham-on-the-Wolds, Melton Mowbray, Leicestershire LE14 4RT, UK \\ ${ }^{2}$ VetCT, St John's Innovation Centre, Cowley Road, Milton, Cambridge CB4 OWS, UK
}

(Submitted 6 February 2017 - Final revision received 20 April 2017 - Accepted 1 May 2017)

\section{Abstract}

Although the implications of long-term high Ca intakes have been well documented in growing dogs, the health consequences of Ca excess in adult dogs remain to be established. To evaluate the impact of feeding a diet containing $7 \cdot 1 \mathrm{~g} / 4184 \mathrm{~kJ}$ ( $1000 \mathrm{kcal}$ ) Ca for $40 \mathrm{weeks}$ on Ca balance and health parameters in adult dogs, eighteen neutered adult Labrador Retrievers, (nine males and nine females) aged 2.5-7.4 years were randomised to one of two customised diets for 40 weeks. The diets were manufactured according to similar nutritional specifications, with the exception of $\mathrm{Ca}$ and P levels. The diets provided 1.7 and $7 \cdot 1 \mathrm{~g} / 4184 \mathrm{~kJ}(1000 \mathrm{kcal})(200$ (SD 26$)$ and 881 (sD 145$) \mathrm{mg} / \mathrm{kg} \mathrm{body} \mathrm{weight}{ }^{0.75}$ per $\mathrm{d}$, respectively) $\mathrm{Ca}$, respectively, with a Ca:P ratio of $1 \cdot 6$. Clinical examinations, ultrasound scans, radiographs, health parameters, metabolic effects and mineral balance were recorded at baseline and at 8-week intervals throughout the study. Dogs in both groups were healthy throughout the trial without evidence of urinary, renal or orthopaedic disease. In addition, there were no clinically relevant changes in any of the measures made in either group (all $P>0 \cdot 05$ ). The high-Ca diet resulted in a 3.3-fold increase in faecal Ca excretion $(P<0 \cdot 001$ ), whereas apparent Ca digestibility (\%) and net Ca balance $(\mathrm{g} / \mathrm{d})$ did not significantly change from baseline or differ between the groups at any time point (both $P>0.05)$. Ca intakes of up to $7 \cdot 1 \mathrm{~g} / 4184 \mathrm{~kJ}(1000 \mathrm{kcal})$ are well tolerated over a period of 40 weeks, with no adverse effects that could be attributed to the diet or to a high mineral intake.

Key words: Canine nutrition: Mineral balance: Digestibility: Calcium:phosphorus ratio

Ca homoeostasis is tightly regulated in most vertebrate species through the interaction between several organs and glands such as bone, gut, kidney, intestines and the parathyroid gland. Ca concentrations in circulation are mediated through the actions of the parathyroid hormone (PTH) and calcitonin ${ }^{(1)}$, although $\mathrm{Ca}$ homoeostasis is also maintained through adjustments in intestinal absorption. Ca absorption in the mammalian small intestine occurs via two mechanisms: a transcellular active transport process, located largely in the duodenum and upper jejunum; and a paracellular, passive process that is present throughout the intestine. When Ca intake is low, transcellular Ca transport accounts for a substantial fraction of the absorbed $\mathrm{Ca}$. Conversely, when $\mathrm{Ca}$ intake is high, transcellular transport accounts for a minor portion of the absorbed $\mathrm{Ca}$, because of the short intestinal sojourn time and a down-regulation of $\mathrm{Ca}$ transporters dependent on $1,25(\mathrm{OH})_{2} \mathrm{D}^{(2)}$.

Intestinal regulation of $\mathrm{Ca}$ absorption exists across many mammalian species and it has been widely accepted that a degree of regulation was also present in the $\operatorname{dog}^{(3)}$. However, a recent meta-analysis of thirty-five $\mathrm{Ca}$ digestibility studies ${ }^{(4)}$ concluded that the relative Ca faecal excretion is not altered as a result of dietary $\mathrm{Ca}$ in adult dogs across a wide range of dietary $\mathrm{Ca}$ intakes. This finding contrasts with expectations that relative Ca excretion would be very low when dogs are fed diets that provide less $\mathrm{Ca}$ than the requirement, and that $\mathrm{Ca}$ excretion would approximate intake when $\mathrm{Ca}$ is provided above the requirement. Instead, the results of the meta-analysis indicated a positive metabolic balance of $\mathrm{Ca}$, where intake exceeded excretion by more than $11 \%$ across a wide range of $\mathrm{Ca}$ intakes and was not affected by dog breed or the Ca source. A subsequent study ${ }^{(5)}$ evaluated the impact of a diet containing $\mathrm{Ca}$ at the National Research Council minimum requirement ${ }^{(6)}$ of $0.5 \mathrm{~g} / 4184 \mathrm{~kJ}(1000 \mathrm{kcal})$ in eleven adult female dogs (six Beagle and five Foxhound cross-breeds) over 6 months. This study concluded that despite the low Ca intake throughout the period of feeding, there was seemingly no adaptation in Ca fractional excretion leading to a negative Ca balance. In addition, an increase in circulating PTH and vitamin D-metabolite concentrations as a result of the reduced $\mathrm{Ca}$ intake was not detected, as might have been expected.

Abbreviations: BW, body weight; iCa, ionised Ca; PTH, parathyroid hormone.

* Corresponding author: Dr P. Watson, fax +44 1664 415440, email Phillip.Watson@effem.com 
This raises questions regarding the long-term adaptability of adult dogs to high dietary $\mathrm{Ca}$. Lack of adaptation of faecal $\mathrm{Ca}$ excretion in response to high intake may result in either a positive $\mathrm{Ca}$ balance or an increase in urinary $\mathrm{Ca}$ excretion; however, previous data from growing $\operatorname{dogs}{ }^{(7)}$ showed that urinary $\mathrm{Ca}$ excretion is generally low even when dogs were fed diets with high $\mathrm{Ca}$ content. Under conditions of long-term Ca excess, tissues may act as stores for $\mathrm{Ca}$ (e.g. bone) through changes in the degree of mineralisation. This has been demonstrated during growth and development, with abnormal skeletal development observed in large and giant-breed pups fed diets containing $\geq 5.5 \mathrm{~g} / 4184 \mathrm{~kJ}(1000 \mathrm{kcal}) \mathrm{Ca}^{(3,7)}$, but data from adult dogs are not currently available.

In humans, long-term dietary Ca excess of $2 \cdot 4-4.6 \mathrm{~g} / \mathrm{d}$ for up to a year has been implicated to cause adverse effects, including decreased dietary bioavailability of minerals such as $\mathrm{Mg}$ and $\mathrm{Zn}$, increased incidence of hypercalcaemia, hypercalciuria, urolithiasis, nephrolithiasis and non-reversible soft tissue calcification $^{(8)}$. Dietary Reference Intakes for Ca and vitamin D have been reviewed by the Institute of Medicine on the basis of recent evidence related to both skeletal and extraskeletal outcomes $^{(9)}$. Former guidelines, set in 1997, established a tolerable upper intake level (UL; the highest daily intake of the nutrient that is likely to pose no risk) for Ca at $2500 \mathrm{mg} / \mathrm{d}$ for all ages above 1 year, whereas the revised UL for Ca now range from $1000-3000 \mathrm{mg} / \mathrm{d}$, depending on life-stage group ${ }^{(9)}$.

Present guidelines for feeding adult dogs with $\mathrm{Ca}$ are based largely on data extrapolated from growth studies ${ }^{(6,10)}$; consequently, the implications of long-term feeding of a high-Ca diet to adult dogs remain unclear. Therefore, the current study aimed to evaluate the impact of feeding a high-Ca diet for 40 weeks on $\mathrm{Ca}$ balance in adult dogs. Changes in renal function, related hormones and vitamin D metabolites, food intake, diet digestibility, and soft tissue and bone mineralisation were measured to support the mineral balance data and to monitor the health of the dogs.

\section{Methods}

\section{Dogs}

In all, eighteen neutered adult Labrador Retrievers (Labradors; nine males and nine females) aged $2 \cdot 5-7 \cdot 4$ years (median $3 \cdot 2$ years) were selected for this study. All dogs underwent a pretrial health assessment, including a physical examination and haematological, biochemical and urine analysis, to ensure they were eligible for the study. Dogs were assigned to either Control or Test (high-Ca) diet groups. The groups were stratified according to sex, age, body weight (BW), familial affiliation (litter mates) and energy requirements to maintain an ideal body condition score $\left(/ \mathrm{kg} \mathrm{BW}^{0.75}\right)$. The Control group comprised eight dogs, whereas the Test group comprised ten dogs. The research protocol was reviewed and approved by the WALTHAM ${ }^{\odot}$ Animal Welfare and Ethical Review Body and carried out under the authority of the Animals (Scientific Procedures) Act 1986

\section{Diets}

Single batches of two dry extruded diets (the control diet and the high-Ca test diet) were formulated and manufactured by
Table 1. Nutrient composition of the Control and Test diets analysed post manufacture

\begin{tabular}{|c|c|c|}
\hline & Control & Test \\
\hline Ash (\%) & $5 \cdot 2$ & $10 \cdot 7$ \\
\hline Fat $(\%)$ & $12 \cdot 5$ & 11.9 \\
\hline Protein (\%) & $29 \cdot 9$ & $27 \cdot 2$ \\
\hline Total dietary fibre (\%) & $5 \cdot 8$ & $5 \cdot 1$ \\
\hline $\mathrm{Ca}(\mathrm{g} / 4184 \mathrm{~kJ}(1000 \mathrm{kcal}))$ & $1 \cdot 7$ & $7 \cdot 1$ \\
\hline$P(g / 4184$ kJ (1000 kcal)) & $1 \cdot 1$ & $4 \cdot 5$ \\
\hline Ca:P ratio & 1.6 & 1.6 \\
\hline $\mathrm{Na}(\mathrm{g} / 4184$ kJ (1000 kcal)) & $1 \cdot 2$ & $1 \cdot 1$ \\
\hline $\mathrm{K}(\mathrm{g} / 4184 \mathrm{~kJ}(1000 \mathrm{kcal}))$ & 2.6 & 2.5 \\
\hline $\operatorname{Mg}(\mathrm{mg} / 4184 \mathrm{~kJ}(1000 \mathrm{kcal}))$ & 376 & 541 \\
\hline $\mathrm{Fe}(\mathrm{mg} / 4184 \mathrm{~kJ}(1000 \mathrm{kcal}))$ & $42 \cdot 2$ & $80 \cdot 0$ \\
\hline $\mathrm{Cu}(\mathrm{mg} / 4184 \mathrm{~kJ}(1000 \mathrm{kcal}))$ & $2 \cdot 3$ & $2 \cdot 7$ \\
\hline Mn (mg/4184 kJ (1000 kcal)) & $18 \cdot 5$ & $17 \cdot 7$ \\
\hline Zn (mg/4184 kJ (1000 kcal)) & 51 & 53 \\
\hline I (mg/4184 kJ (1000 kcal)) & 1.3 & $1 \cdot 3$ \\
\hline $\operatorname{Se}(\mu \mathrm{g} / 4184 \mathrm{~kJ}(1000 \mathrm{kcal}))$ & 107 & 105 \\
\hline Chloride (g/4184 kJ (1000 kcal)) & 2.3 & $2 \cdot 4$ \\
\hline Vitamin A ( $\mu \mathrm{g} / 4184 \mathrm{~kJ}(\mu \mathrm{g} / 1000 \mathrm{kcal}))$ & 1076 & 1362 \\
\hline Vitamin E (mg/4184 kJ (mg/1000 kcal)) & 89 & 112 \\
\hline Thiamin (mg/4184 kJ (1000 kcal)) & $1 \cdot 7$ & $2 \cdot 0$ \\
\hline Riboflavin (mg/4184 kJ (1000 kcal)) & $1 \cdot 2$ & $1 \cdot 0$ \\
\hline Niacin/nicotinic acid (mg/4184 kJ (1000 kcal)) & $13 \cdot 3$ & $11 \cdot 8$ \\
\hline Pyridoxine (mg/4184 kJ (1000 kcal)) & $2 \cdot 6$ & $2 \cdot 3$ \\
\hline Pantothenic acid (mg/4184 kJ (1000 kcal)) & 8.0 & $7 \cdot 0$ \\
\hline Folic acid $(\mu \mathrm{g} / 4184 \mathrm{~kJ}(1000 \mathrm{kcal}))$ & 483 & 358 \\
\hline Cyanocobalamin $(\mu \mathrm{g} / 4184 \mathrm{~kJ}(1000 \mathrm{kcal}))$ & 12 & 12 \\
\hline Choline (g/4184 kJ (1000 kcal)) & 669 & 584 \\
\hline Vitamin $D_{3}(\mu \mathrm{g} / 4184 \mathrm{~kJ}(\mu \mathrm{g} / 1000 \mathrm{kcal}))$ & $5 \cdot 2$ & $5 \cdot 0$ \\
\hline Base excess (MEq/kg)* & 175 & 175 \\
\hline
\end{tabular}

${ }^{*}$ Base excess $=\left(\left[\mathrm{Ca}^{2+}\right]+\left[\mathrm{Mg}^{2+}\right]+\left[\mathrm{Na}^{+}\right]+\left[\mathrm{K}^{+}\right]\right)-\left(\left[\mathrm{PO}_{4}{ }^{3-}\right]+\left[\mathrm{SO}_{4}{ }^{2-}\right]+\left[\mathrm{Cl}^{-}\right]\right)$.

Royal Canin using similar ingredients and ratios to provide a similar nutrient composition, base excess and $\mathrm{Ca}: \mathrm{P}$ ratio (Table 1). To achieve this, both diets were composed of similar quantities of pork meal, animal fat, soya and fish oils, beet pulp, cereal and flavourings, with the additional $\mathrm{Ca}$ and $\mathrm{P}$ in the test diet provided through a combination of bone ash from protein meal and supplemented calcium carbonate. The high-Ca diet provided $7 \cdot 1 \mathrm{~g} \mathrm{Ca} / 4184 \mathrm{~kJ}$ ( $1000 \mathrm{kcal})$, whereas the control diet provided $1.7 \mathrm{~g} \mathrm{Ca} / 4184 \mathrm{~kJ}$ ( $1000 \mathrm{kcal})$; these inclusion levels correspond to 710 and $170 \%$ of the National Research Council recommended allowance for the test and the control diets, respectively ${ }^{(6)}$. The nutrient composition of both diets were analysed at the Mars Petcare Europe Central Laboratory post production, and were compliant with both the American Association of Feed Control Officials ${ }^{(10)}$ and the National Research Council $^{(6)}$ recommended allowance values for adult dogs.

\section{Study design}

All dogs were fed the control diet during the first 9 weeks of the study. Baseline measures were obtained during weeks 8 and 9. Afterwards, the Test group was transitioned to a high-Ca diet for a period of 40 weeks, whereas the Control group remained on the control diet. At the end of the test diet feeding, the Test group was transitioned back to the control diet for an additional 5 weeks until the conclusion of the study.

Dogs were housed according to their diet groups for the duration of the study. During the days of urine and faeces 
sample collection, dogs were housed individually and monitored $24 \mathrm{~h} / \mathrm{d}$ to ensure all samples were collected and the dogs did not practice coprophagia. When individually housed, dogs were still in the company of other dogs and were allowed $1 \mathrm{~h} / \mathrm{d}$ of supervised play interaction with their group. Food intake and faecal quality were recorded daily. Fasted BW and body condition score ${ }^{(11)}$ were recorded weekly. Food provision was adjusted weekly for each dog to maintain an ideal body condition score. All dogs had a full physical examination performed by a researcher (J. S.) at each sampling occasion.

Diet digestibility, mineral balance, glomerular filtration rate (GFR) and blood sampling for the health parameters outlined below were performed at baseline and at 8 -week intervals $(8,16,24,32$ and 40 weeks) throughout the study. Radiography and abdominal ultrasound scanning were performed at the beginning of the first test week and at subsequent 8-week intervals. Dual-energy X-ray absorptiometry (DXA) was conducted at baseline and at weeks 24 and 40. Urine super saturation was assessed at weeks 8, 16, 24, 32, 40 and 48.

\section{Tests and measures - complete blood count (haematology), biochemistry and ionised calcium}

A total of $1 \mathrm{ml}$ of blood was drawn via the jugular veins on each sampling occasion. The blood was divided to three tubes (EDTA-2 $\times$ heparin) for immediate analysis. Complete blood counts were conducted using $0.2 \mathrm{ml}$ of whole blood in EDTA using a haematology analyser (Mythic 18; Orphée SA). Plasma was separated from $0.5 \mathrm{ml}$ of heparinised blood via centrifugation at $1999 \boldsymbol{g}$ for $10 \mathrm{~min}$ at $4^{\circ} \mathrm{C}$ before analysis for biochemical variables (Olympus AU400 Biochemistry Analyzer; Beckman Coulter Inc.). Ionised $\mathrm{Ca}$ (iCa), blood $\mathrm{pH}$ and blood gas analysis was conducted using $0.3 \mathrm{ml}$ of heparinised whole blood (Stat Profile Prime Critical Care Analyser; Woodley Equipment Company Ltd).

\section{Parathyroid hormone, vitamin D metabolites, serum} cross-laps (C-terminal telopeptide) and bone alkaline phosphatase

A $7 \mathrm{ml}$ blood sample was divided between two gel-activated clot tubes and allowed to clot for a minimum of $1 \mathrm{~h}$ before centrifugation for $10 \mathrm{~min}$ at $1999 \boldsymbol{g}$ at room temperature. The resultant serum samples were stored at $-80^{\circ} \mathrm{C}$ before being shipped on dry ice to external laboratories. Analysis of serum PTH, vitamin D metabolites, serum cross-laps and bone alkaline phosphatase (BAP) were conducted at Alomed, Radolfzell, Germany. PTH was analysed using a direct luminometric sandwich-immunoassay, which has been internally validated in dogs. 25- $(\mathrm{OH})$-vitamin $\mathrm{D}_{2}$ and 25-(OH)-vitamin $\mathrm{D}_{3}$ were analysed by HPLC and 1,25-(OH) $)_{2}$-vitamin $\mathrm{D}_{3}$ was determined by RIA. The bone formation marker BAP was analysed using a canine-specific enzyme-immunoassay (MicroVue Bone Health BAP EIA Kit; Quidel); the bone resorption marker serum cross-laps, which recognises the cross-linked carboxyterminal telopeptides of type I collagen (CTx) concentrations in the serum, was analysed using a canine-specific ELISA kit (CTX-1 ELISA; IDS).

\section{Urinalysis}

A $5 \mathrm{ml}$ freshly voided urine sample was collected from each dog and analysed within $30 \mathrm{~min}$ for $\mathrm{pH}$, glucose, protein, blood and Hb (Siemens Multistix 10SG; Siemens AG). Following collection, specific gravity was assessed using a refractometer (Sinotech RHCN-200ATC; Sinotech). The urine was then centrifuged at $9391 \boldsymbol{g}$ for $5 \mathrm{~min}$ and the sediment was separated and evaluated under $20 \times$ magnification for evidence of crystals, erythrocytes, leucocytes, bacteria or casts. Urine albumin was measured with a canine-specific ELISA (ab157685; Abcam PLC) and urinary creatinine was measured using the Beckman Coulter creatinine assay (OSR6178; Olympus AU400 biochemistry analyser). The urinary albumin:creatinine ratio was then calculated for each sample.

\section{Glomerular filtration rate}

GFR was determined using the iohexol clearance method ${ }^{(12)}$. In brief, $300 \mathrm{mg} \mathrm{I} / \mathrm{kg}$ iohexol was administered over a 3-min period, via a cephalic catheter, followed by a heparinised saline flush. The completion of the injection represented timezero. Blood samples of $2 \mathrm{ml}$ volume were collected from the cephalic vein into gel-activated serum clot tubes at 2, 3 and $4 \mathrm{~h}$ post iohexol infusion. Blood samples were then centrifuged at $1999 \boldsymbol{g}$ for $10 \mathrm{~min}$, with the resulting serum frozen at $-80^{\circ} \mathrm{C}$ until analysis. Iohexol concentration in the serum of each dog at each time point was analysed using High-performance capillary electrophoresis (undertaken by the Department of Comparative and Biomedical Sciences, The Royal Veterinary College, London). Clearance (in $\mathrm{ml} / \mathrm{kg}$ per $\mathrm{min}$ ) was calculated using the slope of the concentration gradient over the three time points.

\section{Imaging}

Ventrodorsal and right lateral recumbent radiographs (AGFA CR 30-X, exposure 46-64kV, 2.36-4.73 mAs; AGFA) and ultrasound scans (GE Logiq-E with microconvex probe $(8 \mathrm{C})$, frequency range of $4 \cdot 0-10 \cdot 0 \mathrm{MHz}$ ) were acquired at each time point. Examinations were performed in right followed by left lateral recumbency with the dogs under sedation (induced through administration of $0 \cdot 25 \mathrm{mg} / \mathrm{kg}$ Butorphanol, $10 \mu \mathrm{g} / \mathrm{kg}$ Medetomidine and $0.2 \mathrm{mg} / \mathrm{kg}$ Midazolam). All scans and interpretation of the radiographs were carried out by a boardcertified veterinary radiologist (H. R.). DXA (Encore ${ }^{\mathrm{TM}} 2006$, 10.50 software; GE Lunar Prodigy Advance) was also performed to determine bone mineral density $\left(\mathrm{BMD} ; \mathrm{g} / \mathrm{cm}^{2}\right.$ ) and bone mineral content (BMC; g). The dogs underwent a short sedation (as described above) for the completion of this procedure and analysis was carried out in the supine position.

\section{Mineral balance and apparent digestibility}

Faeces and urine were collected over 5 consecutive days at each time point. Urine was collected via a free-catch method. In the case of urine spillage or a missed sample collection, urine volumes were estimated according to the urination duration and size of the puddle/carpet stain. Urine samples were analysed for $\mathrm{Ca}, \mathrm{Mg}$ (flame photometry) and $\mathrm{P}$ (spectral photometry) content, with these data used to determine the urinary fractional excretion of these minerals. 
Faeces were stored frozen at $-20^{\circ} \mathrm{C}$ in a sealed container until processing. Each pooled $5 \mathrm{~d}$ faecal collection was weighed and then freeze-dried (One VirTis BenchTop BTP9ES Freeze Dryer; Biopharma Process Systems). Once dried, the faeces were weighed again and manually homogenised in a mortar and pestle. Any foreign bodies, such as rocks and plant material, were removed and weighed separately. A $50 \mathrm{~g}$ aliquot of the homogenate was sent for laboratory analysis, which included fat, protein, DM, organic matter, fibre, ash, $\mathrm{Ca}, \mathrm{P}, \mathrm{Zn}$ and $\mathrm{Mg}$ analysis. Apparent protein, fat, DM and mineral digestibility were calculated as the difference between the dietary intake and faecal content over the 5 collection days and expressed as percentage of the intake. The total mineral balance $(\mathrm{g})$ was also calculated for $\mathrm{Ca}, \mathrm{P}$ and $\mathrm{Mg}$ as intake - (faecal excretion + urinary excretion).

\section{Urine mineral content and relative super saturation}

All passed urine was collected over a $5 \mathrm{~d}$ period. The method for urine relative super saturation (RSS) analysis has been previously described ${ }^{(13)}$. Samples were analysed for oxalate, citrate, pyrophosphate, $\mathrm{K}, \mathrm{Ca}, \mathrm{Na}$, ammonium, chloride, sulphate and phosphate via HPLC. The concentrations of analytes were then used by SUPERSAT software (Institute of Urology and Nephrology, University College) to calculate the RSS (activity product/solubility product) for struvite and Ca oxalate. This analysis is carried out at the Royal Canin SAS European Regional Laboratory in Aimargues, France.

\section{Statistical analysis}

Power analyses by simulation were performed for the primary response variable (the percentage difference in intake and excreted Ca levels $\left(\mathrm{mg} / \mathrm{kg}^{0.75}\right)$. Data from a previous study ${ }^{(5)}$ evaluating faecal $\mathrm{Ca}$ excretion were used to estimate the between-dog variability to enable simulation of data sets. Using this methodology, it was found that ten dogs were needed in the Test group when using eight dogs in the Control group to detect a $6 \%$ reduction, from a baseline of $12 \%$, in the percentage difference in percentage retention of $\mathrm{Ca}$ with at least $80 \%$ power.

Data are presented as means with $95 \%$ CI. The data were analysed using linear mixed effects models with each measure as the response. Fixed effects of diet, sampling occasion and their interaction, and a random effect of dog, to account for the repeat measurements, were examined. Three sets of hypothesis tests were performed: first, the difference between groups at each of the six sampling occasions; second, the change from baseline of each time point within each diet group; and finally, the difference in the change from baseline between diet groups. All analyses were performed using $\mathrm{R}$ version 3.2.0 with the lme4 and multcomp libraries, and the hypothesis tests were corrected for multiplicity to control the family-wise error rate to a level of $5 \%$.

\section{Results}

\section{General health data}

Of the eighteen Labrador Retrievers initially included, seventeen completed the full 56 weeks of the study. One female (aged 8.2 years) from the Test diet group was removed from the study in week 27 because of the diagnosis of a hepatic mass on abdominal ultrasound scanning. The dog underwent a subsequent laparotomy and a partial hepatectomy, which revealed a benign hyperplastic mass. All other dogs were assessed as healthy and free of any clinical signs of adverse dietary effects

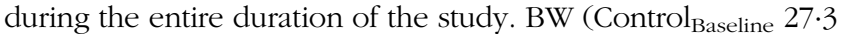
(95\% CI $24 \cdot 7,29 \cdot 9) \mathrm{kg}$, Control End $_{27.0}(95 \%$ CI $24 \cdot 5,29 \cdot 6) \mathrm{kg}$; Test $_{\text {Baseline }} 27.2$ (95\% CI 25.0, 29.5) kg, Test End $_{27.2}$ (95\% CI $24.9,29.5) \mathrm{kg} ; P=1.000)$ and energetic intake (Control Baseline $418(95 \%$ CI 347,490$) \mathrm{kJ} / \mathrm{kg}^{0.75}$, Control End $_{397}(95 \%$ CI 331, 469) kJ/kg ${ }^{0.75}$; Test Baseline 448 (95\% CI 385, 510) kJ/kg ${ }^{0.75}$, Test $_{\text {End }} 452\left(95 \%\right.$ CI 385, 515) kJ/kg $\left.{ }^{0.75} ; P=1.000\right)$ were not significantly different between the groups at any time. Following the baseline period, Ca intake was 200 (SD 26) $\mathrm{mg} / \mathrm{kg}$ $\mathrm{BW}^{0.75}$ per $\mathrm{d}$ for the Control group and $881(\mathrm{sD} 145) \mathrm{mg} / \mathrm{kg}$ $\mathrm{BW}^{0.75}$ per $\mathrm{d}$ in the Test group.

All of the health-related measures (e.g. haematology, serum biochemistry) remained within normal ranges throughout the study and none showed consistent significant differences between the groups $(P>0 \cdot 05)$. iCa concentrations were not different between groups before the intervention (Control 1.21 (95\% CI 1.18, 1.25) mmol/l; Test 1.23 (95\% CI 1.20, 1.26) mmol/1; $P=0.995)$. Although there was a tendency for iCa concentrations to be lower in the Test group compared with the Control group at week 8 (Control 1.27 (95\% CI 1.21, 1.33) mmol/l; Test 1.20 (95\% CI $1.17,1.23) \mathrm{mmol} / \mathrm{l} ; P=0.065)$, no significant differences over time $(P>0.05)$ or between groups $(P>0.05)$ were apparent throughout the study.

\section{Imaging}

Of the seventeen dogs that completed the study, one dog was radiographed on the three initial occasions, but only underwent ultrasonographic examinations for the subsequent three time points because of concerns over response to sedation. No evidence of urolithiasis or soft tissue mineralisation was detected on any occasion using either modality. Ultrasound scans highlighted mild pyelectasia in eleven of the dogs (seven from the Control group, four from the Test group) on a single occasion during the study; however, this finding was transient and was not evident in follow-up scans.

\section{Renal and urinary health}

Serum creatinine and urea were not significantly different between the groups at any time point or over time, with the exception of week 40 when both were significantly higher in the Control group (Table 2; $P=0 \cdot 005$ ). GFR calculated using the iohexol clearance method (Fig. 1) was reduced compared with baseline in both groups until 32 weeks $(P<0.05)$, with no differences apparent between the two groups at any time point $(P>0.05)$. Urine-specific gravity and the urinary albumin: creatinine ratio did not change during the study or show significant differences between the groups on any occasion. RSS for both calcium oxalate and for magnesium ammonium triphosphate (struvite) did not show significant differences in the between groups change from baseline (Table 2). There was no evidence of urinary tract disease in any dog during the study. 
Table 2. Renal and urinary health measures* (Mean values and $95 \%$ confidence intervals)

\begin{tabular}{|c|c|c|c|c|c|}
\hline \multirow[b]{2}{*}{ Weeks } & \multicolumn{2}{|c|}{ Control } & \multicolumn{2}{|c|}{ Test } & \multirow[b]{2}{*}{$P$} \\
\hline & Mean & $95 \% \mathrm{Cl}$ & Mean & $95 \% \mathrm{Cl}$ & \\
\hline \multicolumn{6}{|c|}{ Serum creatinine $(\mu \mathrm{mol} / \mathrm{l})$} \\
\hline Baseline & 112.4 & $104 \cdot 0,121.5$ & $112 \cdot 2$ & $104 \cdot 7,120 \cdot 3$ & 1.000 \\
\hline 8 & 114.5 & $105 \cdot 9,123 \cdot 7$ & 108.8 & $101 \cdot 5,116.7$ & 0.883 \\
\hline 16 & $116 \cdot 1$ & $107 \cdot 4,125 \cdot 5$ & $115 \cdot 3$ & $107 \cdot 6,123 \cdot 6$ & 1.000 \\
\hline 24 & $116 \cdot 6$ & $107 \cdot 9,126 \cdot 0$ & 112.5 & $104 \cdot 9,120 \cdot 6$ & 0.987 \\
\hline 32 & $122 \cdot 9$ & $113 \cdot 7,132 \cdot 9$ & $112 \cdot 1$ & $104 \cdot 4,120 \cdot 4$ & 0.193 \\
\hline 40 & $131 \cdot 1$ & $121 \cdot 3,141 \cdot 6$ & $113 \cdot 3$ & $105 \cdot 5,121 \cdot 6$ & 0.005 \\
\hline \multicolumn{6}{|c|}{ Serum urea $(\mathrm{mmol} / \mathrm{l})$} \\
\hline Baseline & $5 \cdot 8$ & $5 \cdot 1,6 \cdot 7$ & $6 \cdot 5$ & $5 \cdot 7,7 \cdot 3$ & 0.800 \\
\hline 8 & 5.5 & $4.8,6.4$ & $5 \cdot 0$ & $4 \cdot 4,5 \cdot 7$ & 0.787 \\
\hline 16 & $6 \cdot 2$ & $5 \cdot 4,7 \cdot 2$ & $5 \cdot 7$ & $5 \cdot 0,6 \cdot 4$ & 0.851 \\
\hline 24 & $6 \cdot 3$ & $5 \cdot 5,7 \cdot 3$ & $5 \cdot 8$ & $5.1,6.5$ & 0.902 \\
\hline 32 & $6 \cdot 2$ & $5 \cdot 4,7 \cdot 2$ & 5.7 & $5 \cdot 0,6 \cdot 4$ & 0.859 \\
\hline 40 & $6 \cdot 5$ & $5 \cdot 7,7 \cdot 5$ & $5 \cdot 3$ & $4 \cdot 7,6 \cdot 0$ & 0.058 \\
\hline \multicolumn{6}{|c|}{ Urine-specific gravity } \\
\hline Baseline & 1.023 & $1.010,1.035$ & 1.026 & $1.015,1.037$ & 1.000 \\
\hline 8 & 1.018 & $1.005,1.030$ & 1.020 & $1.008,1.031$ & 1.000 \\
\hline 16 & 1.022 & $1.010,1.035$ & 1.020 & $1.009,1.031$ & 1.000 \\
\hline 24 & 1.024 & $1.011,1.036$ & 1.015 & $1.004,1.026$ & 0.844 \\
\hline 32 & 1.017 & $1.004,1.029$ & 1.010 & $0.999,1.022$ & 0.977 \\
\hline 40 & 1.019 & $1.006,1.031$ & 1.018 & $1.006,1.029$ & 1.000 \\
\hline \multicolumn{6}{|c|}{ Urine RSS struvite } \\
\hline 8 & 2.50 & $0.44,14 \cdot 10$ & 0.15 & $0.03,0.73$ & 0.015 \\
\hline 16 & 1.83 & $0 \cdot 32,10 \cdot 31$ & $0 \cdot 18$ & $0.04,0.84$ & 0.078 \\
\hline 24 & 1.25 & $0.22,7.07$ & 0.30 & $0.06,1.41$ & 0.651 \\
\hline 32 & 1.30 & $0.23,7.31$ & $0 \cdot 10$ & $0.02,0.49$ & 0.039 \\
\hline 40 & 0.49 & $0.09,2.74$ & 0.12 & $0.02,0.58$ & 0.672 \\
\hline 48 & 0.21 & $0.04,1.17$ & 0.34 & $0.07,1.65$ & 1.000 \\
\hline \multicolumn{6}{|c|}{ Urine RSS calcium oxalate } \\
\hline 8 & 2.58 & $1.03,6.43$ & 2.07 & $0.92,4.70$ & 1.000 \\
\hline 16 & $3 \cdot 61$ & $1.45,8.99$ & 2.04 & $0.90,4.62$ & 0.909 \\
\hline 24 & $2 \cdot 18$ & $0.87,5.43$ & 1.71 & $0.75,3.86$ & 1.000 \\
\hline 32 & 2.59 & $1.04,6.46$ & 1.54 & $0.67,3.56$ & 0.951 \\
\hline 40 & $2 \cdot 80$ & $1 \cdot 12,6 \cdot 98$ & $3 \cdot 28$ & $1.42,7.55$ & 1.000 \\
\hline 48 & $2 \cdot 36$ & $0.95,5.89$ & $3 \cdot 16$ & $1 \cdot 37,7 \cdot 29$ & 0.999 \\
\hline
\end{tabular}

RSS, relative super saturation.

* $P$ values represent comparison between groups at the given time point.

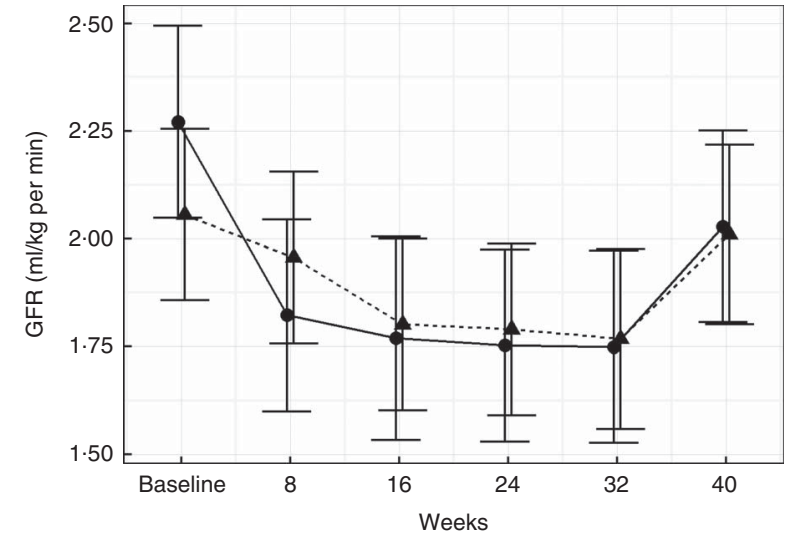

Fig. 1. Glomerular filtration rate (GFR) measured throughout the study in both the Control (- - ) and the Test (- - - ) groups. Values are means and $95 \% \mathrm{Cl}$.

\section{Bone health and related hormones}

DXA measurements for bone mineralisation including BMD $\left(\mathrm{g} / \mathrm{cm}^{2} ; P>0.05\right)$ and BMC (g; $\left.P>0.05\right)$ were not significantly different between the Control and the Test groups in any of the measurements (Table 3). Similarly, bone formation (BAP; $P>0.05$ ) and bone resorption markers (serum CTx; $P>0.05$ ) as well as the measured hormones and vitamin D metabolites (PTH, fibroblast growth factor 23 (FGF23), calcidiol and calcitriol) were not significantly different between the groups at any time point (Table 3).

\section{Mineral balance and apparent digestibility}

There was no difference in faecal $\mathrm{Ca}$ excretion between the groups at baseline $(P=0.913)$. Ingestion of the Test diet resulted in a $3 \cdot 3$-fold elevation in faecal $\mathrm{Ca}$ excretion for the remainder of the study $(P<0 \cdot 001)$, with no change apparent in the Control group (Fig. 2(a)). Urinary Ca excretion was increased in the Test group at weeks 8, 16, 24 and 40 (Fig. 2(a); $P<0.05$ ), although urinary $\mathrm{Ca}$ losses remained considerably lower than those measured in the faeces. Consequently, total Ca balance was not significantly different from 0 at any time point in either group (Fig. 2(b)). The estimated difference between groups in the change in Ca balance over the duration of the study was 0.85 $(95 \% \mathrm{CI}-1.67,3.36) \mathrm{g}(P=0.983)$. A linear regression of dietary 
Table 3. Bone measures and related hormones* (Mean values and $95 \%$ confidence intervals)

\begin{tabular}{|c|c|c|c|c|c|}
\hline \multirow[b]{2}{*}{ Weeks } & \multicolumn{2}{|c|}{ Control } & \multicolumn{2}{|c|}{ Test } & \multirow[b]{2}{*}{$P$} \\
\hline & Mean & $95 \% \mathrm{Cl}$ & Mean & $95 \% \mathrm{Cl}$ & \\
\hline \multicolumn{6}{|c|}{ DXA BMC (g) } \\
\hline Baseline & 965 & 838,1110 & 939 & 828,1065 & 0.999 \\
\hline 24 & 937 & 815,1078 & 927 & 817,1050 & 1.000 \\
\hline 40 & 961 & 836,1106 & 956 & 843,1084 & 1.000 \\
\hline \multicolumn{6}{|c|}{ DXA BMD (g/cm²) } \\
\hline Baseline & 0.99 & $0.94,1.05$ & 0.99 & $0.94,1.04$ & 1.000 \\
\hline 24 & 1.00 & $0.94,1.06$ & 1.00 & $0.95,1.06$ & 1.000 \\
\hline 40 & 1.00 & $0.94,1.06$ & 1.00 & $0.95,1.06$ & 1.000 \\
\hline \multicolumn{6}{|c|}{ Bone alkaline phosphatase (UL) } \\
\hline Baseline & 8.9 & $6 \cdot 9,11.6$ & $9 \cdot 3$ & $7 \cdot 3,11 \cdot 7$ & 1.000 \\
\hline 8 & $11 \cdot 0$ & $8 \cdot 5,14 \cdot 3$ & 9.5 & $7 \cdot 5,12 \cdot 0$ & 0.942 \\
\hline 16 & 8.2 & $6 \cdot 3,10 \cdot 7$ & 9.6 & $7 \cdot 6,12 \cdot 2$ & 0.919 \\
\hline 24 & $8 \cdot 3$ & $6 \cdot 4,10 \cdot 8$ & 8.5 & $6 \cdot 7,10 \cdot 8$ & 1.000 \\
\hline 32 & 9.8 & $7 \cdot 6,12 \cdot 8$ & 9.4 & $7 \cdot 3,12 \cdot 0$ & 1.000 \\
\hline 40 & 9.9 & $7 \cdot 6,12 \cdot 9$ & $9 \cdot 1$ & $7 \cdot 1,11 \cdot 6$ & 0.999 \\
\hline \multicolumn{6}{|c|}{ Serum cross-laps (ng/ml) } \\
\hline Baseline & 0.83 & $0.41,1.67$ & 0.48 & $0.27,0.86$ & 0.711 \\
\hline 8 & 0.76 & $0.38,1.54$ & 0.45 & $0.25,0.81$ & 0.758 \\
\hline 16 & 0.60 & $0.30,1.21$ & 0.38 & $0.21,0.68$ & 0.880 \\
\hline 24 & 0.72 & $0.36,1.45$ & 0.53 & $0.30,0.96$ & 0.992 \\
\hline 32 & 0.37 & $0.19,0.75$ & 0.42 & $0.23,0.75$ & 1.000 \\
\hline 40 & 0.41 & $0.20,0.82$ & 0.24 & $0.13,0.43$ & 0.748 \\
\hline \multicolumn{6}{|l|}{ PTH (ng/ml) } \\
\hline Baseline & $14 \cdot 2$ & $9 \cdot 4,21 \cdot 4$ & $18 \cdot 3$ & $12 \cdot 9,26 \cdot 0$ & 0.886 \\
\hline 8 & $15 \cdot 4$ & $10 \cdot 4,22 \cdot 7$ & $15 \cdot 6$ & $11 \cdot 0,22 \cdot 2$ & 1.000 \\
\hline 16 & $17 \cdot 8$ & $12 \cdot 0,26 \cdot 2$ & $18 \cdot 6$ & $13 \cdot 1,26 \cdot 4$ & 1.000 \\
\hline 24 & $17 \cdot 3$ & $11 \cdot 7,25 \cdot 5$ & $20 \cdot 8$ & $14.7,29.5$ & 0.980 \\
\hline 32 & $15 \cdot 3$ & $10 \cdot 4,22 \cdot 7$ & $22 \cdot 1$ & $15 \cdot 4,31 \cdot 8$ & 0.487 \\
\hline 40 & 18.6 & $12 \cdot 6,27 \cdot 4$ & 20.5 & $14.2,29 \cdot 5$ & 1.000 \\
\hline \multicolumn{6}{|c|}{ FGF23 (pg/ml) } \\
\hline Baseline & 377 & 305,466 & 486 & 402,587 & 0.169 \\
\hline 8 & 385 & 311,475 & 436 & 355,536 & 0.944 \\
\hline 16 & 390 & 316,482 & 452 & 374,546 & 0.827 \\
\hline 24 & 362 & 293,447 & 432 & 356,524 & 0.661 \\
\hline 32 & 377 & 305,466 & 415 & 343,505 & 0.988 \\
\hline 40 & 401 & 325,496 & 434 & 357,527 & 0.998 \\
\hline \multicolumn{6}{|c|}{ Calcidiol ( $\mu \mathrm{g} / \mathrm{l})$} \\
\hline Baseline & $43 \cdot 8$ & $37.8,50 \cdot 9$ & $43 \cdot 2$ & $37 \cdot 8,49 \cdot 4$ & 1.000 \\
\hline 8 & 39.5 & $34 \cdot 0,45 \cdot 8$ & $36 \cdot 6$ & $32.1,41.9$ & 0.979 \\
\hline 16 & 39.5 & $34 \cdot 0,45 \cdot 8$ & $35 \cdot 0$ & $30 \cdot 6,40 \cdot 0$ & 0.695 \\
\hline 24 & 37.4 & $32 \cdot 2,43 \cdot 4$ & 33.2 & $29.0,37.9$ & 0.709 \\
\hline 32 & $40 \cdot 7$ & $35 \cdot 0,47 \cdot 3$ & 34.2 & $29.8,39.2$ & 0.225 \\
\hline 40 & 38.4 & $33 \cdot 1,44 \cdot 6$ & $35 \cdot 6$ & $31 \cdot 1,40 \cdot 8$ & 0.980 \\
\hline \multicolumn{6}{|c|}{ Calcitriol ( $\mu \mathrm{g} / \mathrm{l})$} \\
\hline Baseline & $16 \cdot 7$ & $12 \cdot 9,21 \cdot 6$ & $15 \cdot 7$ & $12 \cdot 5,19 \cdot 8$ & 1.000 \\
\hline 8 & 14.6 & $11 \cdot 2,18.9$ & $16 \cdot 0$ & $12 \cdot 5,20 \cdot 3$ & 0.999 \\
\hline 16 & $15 \cdot 9$ & $12 \cdot 3,20 \cdot 6$ & $16 \cdot 8$ & $13 \cdot 2,21 \cdot 3$ & 1.000 \\
\hline 24 & $15 \cdot 0$ & $11 \cdot 6,19.5$ & $17 \cdot 6$ & $13 \cdot 8,22 \cdot 4$ & 0.931 \\
\hline 32 & $13 \cdot 0$ & $10 \cdot 0,16 \cdot 8$ & $16 \cdot 7$ & $13 \cdot 1,21 \cdot 2$ & 0.457 \\
\hline 40 & $13 \cdot 2$ & $10 \cdot 2,17 \cdot 1$ & $16 \cdot 0$ & $12 \cdot 6,20 \cdot 4$ & 0.774 \\
\hline
\end{tabular}

DXA, dual-energy X-ray absorptiometry; BMC, bone mineral content; BMD, bone mineral density; UL, upper intake level; PTH, parathyroid hormone FGF23, fibroblast growth factor 23.

${ }^{*} P$ values represent comparison between groups at the given time point.

Ca intake $v$. faecal Ca excretion throughout the study highlighted that the $95 \%$ confidence regions for both diet groups surround the $y-x$ line, supporting the view that there was no difference in the amount of $\mathrm{Ca}$ retained $\mathrm{n}$ either the Control or the Test diets (Fig. 3).

Apparent Ca digestibility was not different between groups at the end of baseline-diet feeding (Control 19.3 (95\% CI $-1 \cdot 1$, $39.7) \%$; Test 5.0 (95\% CI $-2 \cdot 1,22 \cdot 1) \% ; P=0.782)$. With the exception of $\mathrm{Ca}$ digestibility being elevated in the Control group on week 40 ( $P=0.003)$, no further differences between groups were apparent (all $P>0 \cdot 05$ ). There were no significant differences between the groups in $\mathrm{P}$ or $\mathrm{Mg}$ digestibility over the duration of the study. During the 8 weeks following transition to the test diet, $\mathrm{Zn}$ digestibility was reduced compared with baseline (Baseline 3.0 (95\% CI -14.3, 20.3)\%; week $8-23.3$ (95\% CI $-40 \cdot 6,-6 \cdot 0) ; P=0.026)$ and was significantly lower than that in the Control group at the same time point $(P=0 \cdot 009)$. This response was transient, with no differences 
(a)
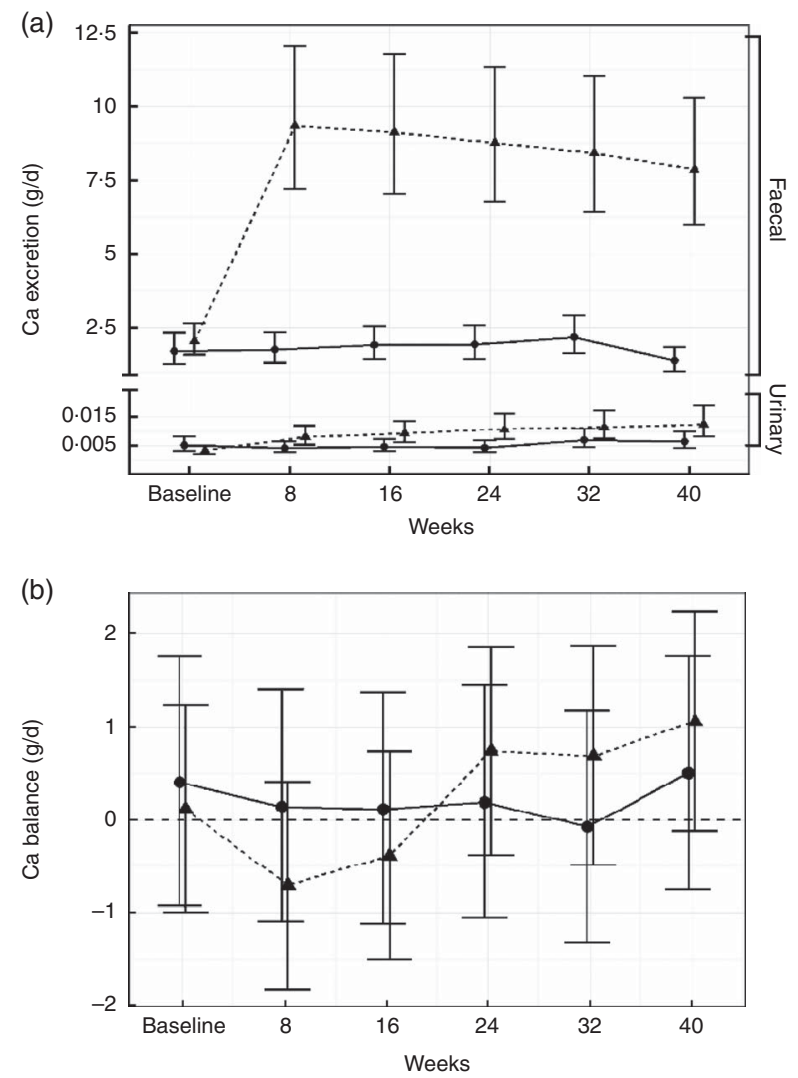

Fig. 2. Faecal and urinary $\mathrm{Ca}$ excretion (a) and Ca balance (b) throughout the study in both the Control (- - ) and the Test (-- $-\mathbf{-}-)$ groups. Values are means and $95 \% \mathrm{Cl}$.

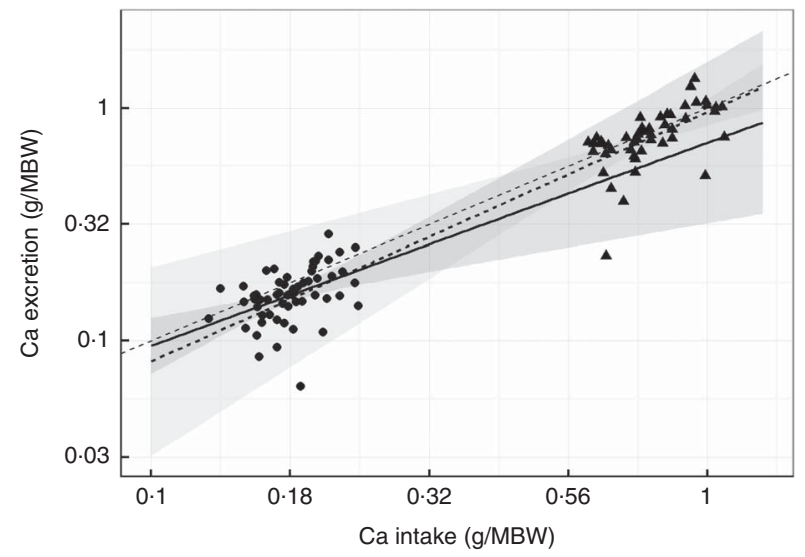

Fig. 3. Linear regression between dietary $\mathrm{Ca}$ intake and faecal $\mathrm{Ca}$ excretion $\left(\mathrm{g} / \mathrm{kg}\right.$ body weight $(\mathrm{BW})^{0.75}$; metabolic body weight (MBW)). The $95 \%$ confidence regions for both diet groups surround the $y-x(----)$, supporting the view that there was no difference in the amount of $\mathrm{Ca}$ retained in either the Control (- - ) or the Test (- - - - -) diets.

compared with the baseline or with the Control group during the remainder of the study $(P>0 \cdot 05)$.

No differences in energy (Control 86.4 (95\% CI 83.6, 89.2)\%; Test $83.8(95 \%$ CI 81.5, 86.2) \%; $P=0.434$ ), protein (Control 85.7 (95\% CI 82.7, 88.6)\%; Test 84.9 (95\% CI 82.4, 87.4)\%; $P=1.000)$ or fat (Control 97.5 (95\% CI 96.7, 98.3)\%; Test $97 \cdot 8$ (95\% CI 97.1, 98.5)\%; $P=1.000)$ digestibility were apparent between groups during baseline feeding. Despite a tendency for a transient fall in protein digestibility during the initial 8 weeks of test diet feeding (Control 85.8 (95\% CI 83.0, 88.6) \%; Test 80.6 (95\% CI $78.1,83.1) \% ; P=0.059$ ), there was no significant change in energy, protein or fat digestibility or any differences between groups throughout the remainder of the study $(P>0 \cdot 05)$. From week 8 , there was a significant reduction in DM digestibility apparent in the high-Ca diet group $(78 \cdot 2$ (95\% CI 76.1, 80.4) \%) when compared with the Control group (88.2 (95\% CI 85.8, 90.6)\%; $P<0.001)$. This response remained until the end of the trial.

\section{Discussion}

The aim of this study was to evaluate the impact of feeding a high-Ca diet on markers of health and Ca balance in adult dogs. Although concerns have been raised regarding the long-term feeding of Ca excess in dogs ${ }^{(4,5,14)}$, the current study showed that both the control and the high-Ca diets were well tolerated, and no dogs displayed gastrointestinal signs, reduced food intake, failure to maintain ideal body condition or any adverse effects that could be attributed to the diet or to a high mineral intake. In addition, there were no consistent differences between the Test and the Control groups in any measured haematological and biochemical parameters, urinalysis, or GFR, which could indicate clinical or sub clinical negative effects as a result of a high $\mathrm{Ca}$ intake. It should be noted that one of the dogs in the Test group was removed from the study in week 27 because of the ultrasonographic diagnosis of a hepatic mass. Histopathology of the mass following excision revealed that the mass was benign and without evidence of mineralisation or any other pathologic finding that could suggest a connection to high Ca intake.

Despite marked differences in dietary $\mathrm{Ca}$ intake, iCa remained stable throughout the study and did not differ between groups at any time point. Regulation of circulating $\mathrm{Ca}$ concentrations involves a complex process, reliant on the integrated actions of PTH, vitamin D metabolites, calcitonin and iCa itself on Ca-sensing receptors expressed in the parathyroid gland and the renal tubules of the kidney ${ }^{(1)}$. Increased dietary $\mathrm{Ca}$ intake results in a reduction in the synthesis and release of PTH, which exerts both direct and indirect effects on the intestine, kidney and bone. Reduced circulating PTH controls the synthesis of calcitriol $\left(1,25(\mathrm{OH})_{2}\right.$-vitamin D) by suppressing renal 1- $\alpha$-hydroxylation of calcidiol $(25(\mathrm{OH})$-vitamin $\mathrm{D})$ derived from the circulation. Through this response, reduced circulating calcitriol concentrations will limit $\mathrm{Ca}$ absorption from the intestine, resulting in an increase in faecal $\mathrm{Ca}$ excretion. In addition, reductions in PTH and calcitriol, in response to high $\mathrm{Ca}$ intakes, will suppress osteoclastic bone resorption and reduce renal $\mathrm{Ca}$ reabsorption. Whereas there was a significant reduction in serum calcitriol concentrations in the Test diet group over the course of the study, at no point was this response different to the corresponding time point in the Control group, suggesting some seasonal variation in this metabolite of vitamin D. In addition, a high dietary Ca intake failed to significantly alter serum PTH concentrations. The lack of a clear diet effect on these measures is surprising, but it may be explained by the nutritional adequacy of both diets (e.g. not 
sufficiently different to elicit a response) and the similar Ca:P ratio (1.6:1) of the control and test diets, or it is possible that some adaptation had already occurred during the first 8 weeks that was missed by the first sample time point.

A high dietary $\mathrm{Ca}$ intake resulted in increases in both faecal and urinary $\mathrm{Ca}$ excretion, with faecal excretion comprising a much greater proportion of overall losses. This observation is consistent with the view that a reduction in intestinal $\mathrm{Ca}$ absorption is a primary mechanism in the regulation of $\mathrm{Ca}$ balance during exposure to excess dietary $\mathrm{Ca}$ in mammalian species ${ }^{(1-3)}$. It is worth noting that faecal excretion is comprised of both unabsorbed dietary $\mathrm{Ca}$, as well as a contribution from endogenous $\mathrm{Ca}$ losses. Further research may help identify whether endogenous losses change in response to marked changes in dietary $\mathrm{Ca}$ intake. $\mathrm{Ca}$ balance and apparent $\mathrm{Ca}$ digestibility (expressed as a percentage of $\mathrm{Ca}$ intake) were not significantly different between dogs fed the control or test diets. As Ca balance was not significantly different from zero for either diet at any time point, the current results do not support the hypothesis that dogs are unable to sufficiently adjust $\mathrm{Ca}$ intestinal absorption to account for an increased Ca intake ${ }^{(4)}$. The results of the present study suggest that maintaining $\mathrm{Ca}$ balance is a somewhat variable process as individual dogs had positive or negative balances at different sampling occasions throughout the trial regardless of diet; this may also represent a phased regulation of $\mathrm{Ca}$ balance, where small quantities of $\mathrm{Ca}$ accumulate up to a threshold that triggers excretion to maintain balance over time. As these effects were neither consistent within diet, or maintained within particular animals over time, overall Ca balance was determined as neutral in both groups, which may hide a more individualised response. It is also worth noting that despite a $2 \cdot 1$-fold increase in urinary Ca excretion, there was no concurrent increase in the RSS for Ca oxalate. Therefore, it would appear that higher $\mathrm{Ca}$ intake does not equate a high risk for $\mathrm{Ca}$ oxalate urolithiasis, at least in the range of intakes studied here.

Previous studies demonstrated that adult dogs exposed to a low Ca intake $(0.5 \mathrm{~g} / 4184 \mathrm{~kJ}(1000 \mathrm{kcal}))$ for 6 months do not appear to adjust their fractional $\mathrm{Ca}$ excretion, leading to a negative $\mathrm{Ca}$ balance and a resulting mobilisation of bone minerals to maintain Ca homoeostasis ${ }^{(5)}$. In contrast, the present study indicates that dogs are able to adequately regulate $\mathrm{Ca}$ balance when diets contain levels above minimum requirements. Given that several studies have highlighted abnormal skeletal growth in large- and giant-breed puppies fed diets containing $\geq 5.5 \mathrm{~g} / 4184 \mathrm{~kJ}$ (1000 kcal) $\mathrm{Ca}^{(3,7)}$, the present data suggest a developmental adaptation enabling adult dogs to regulate Ca uptake from the gastrointestinal tract, thus limiting potential long-term health concerns when fed high-Ca diets. This makes sense from an evolutionary perspective, supporting scavenging behaviours where dogs would have been likely to rapidly consume large, infrequent meals high in Ca-rich bony material, rather than Ca-deficient foods ${ }^{(15)}$.

High dietary $\mathrm{Ca}$ has been suggested to cause chelation of fat and decrease absorption of dietary minerals such as P, Zn and $\mathrm{Mg}$, as demonstrated by studies in humans and rodents ${ }^{(13,16,17)}$. The apparent digestibility and mineral balance results did reveal a transient reduction in $\mathrm{Zn}$ digestibility, but failed to demonstrate an altered faecal excretion of these minerals or a decrease in fat or protein digestibility in the Test group, as might be expected. Similarly, there was no difference in energy intake required to maintain an ideal body condition between the Test and the Control groups. This further supports the conclusion that $\mathrm{Ca}$ intake did not significant influence energy or macronutrient digestibility. A marked reduction in DM digestibility was observed following transition to the test diet, with this response maintained for the duration of the study in this group; this response is most likely driven by the marked difference in the ash content of the experimental diets (Control $5 \cdot 2 \%$, Test $10.7 \%$; Table 1). It was previously suggested that faecal $\mathrm{Ca}$ excretion may be negatively associated with dietary DM digestibility ${ }^{(18)}$. As such, an increase in $\mathrm{Ca}$ absorption could result in a positive $\mathrm{Ca}$ balance in diets with very high digestibility, such as experimental or home-prepared diets. Commercial dog diets contain raw ingredients and undergo processing such as extrusion and cooking, which generally limit DM digestibility, and consequently lower Ca availability. This effect of $\mathrm{Ca}$ on diet digestibility may account for the difference in the findings of the current study, compared with those presented in the meta-analysis by Mack et al. ${ }^{(4)}$ where many of the diets evaluated were experimental diets. It is also worth noting that the studies included in this meta-analysis involved relatively short-term exposure to the experimental diets, and that much of the data were drawn from studies feeding $\mathrm{Ca}$ below minimum requirements, as opposed to intakes comparable with those in the present study.

There are a number of factors that must be considered when translating the results of this study into canine diet formulations. First, dietary factors, including dietary content of phytate, oxalate, fat, the $\mathrm{Ca}$ source and the $\mathrm{Ca}: \mathrm{P}$ ratio are thought to influence $\mathrm{Ca}$ absorption ${ }^{(19)}$; therefore, the diets in the present study will not represent all possible diet formulations available in the market. The source of $\mathrm{Ca}$ in the current test diet was provided by a combination of pork meal and supplemented Ca carbonate. Ca derived from organic raw materials is thought to be less bioavailable than Ca from other sources, but there is evidence to suggest that organic and inorganic forms of Ca have similar bioavailability in many species ${ }^{(4,20)}$. Finally, the present study was conducted in a single adult breed (Labrador Retriever). Previous studies in growing $\operatorname{dogs} s^{(3,7)}$ have documented that the effects of high-Ca diets vary in dogs of different breed sizes and that some implications of high mineral load, such as urolithiasis, are more common in certain breeds ${ }^{(21)}$. Therefore, before generalised recommendations can be made, the impact of high $\mathrm{Ca}$ intakes should be investigated in other breeds.

In conclusion, the current study demonstrates that Ca intakes of up to $7 \cdot 1 \mathrm{~g} / 4184 \mathrm{~kJ}(1000 \mathrm{kcal})$ were well tolerated over a period of 40 weeks, with no adverse effects that could be attributed to the diet or to a high mineral intake. These data provide evidence that adult dogs are able to tolerate higher $\mathrm{Ca}$ intakes than puppies, and this will enable more precise recommendations for a safe $\mathrm{Ca}$ upper limit in adult dogs. In addition, Ca balance was maintained throughout the study and was not significantly different from 0 in either group, at any time point. Under the present study conditions, there was no 
evidence of $\mathrm{Ca}$ bioaccumulation, and the data do not indicate that high $\mathrm{Ca}$ intakes result in persistent reductions in mineral, fat or energy absorption.

\section{Acknowledgements}

The authors would like to acknowledge the skills and expertise of colleagues at WALTHAM in the care and training of the dogs and for the analysis of samples collected throughout the study. The authors recognise the contribution of Jonathan Elliott, Sam Williams and Ludovic Pelligand (The Royal Veterinary College, London) in the analysis and interpretation of the iohexol clearance data. In addition, the authors express their gratitude to Ellen Kienzle and Britta Dobenecker (Ludwig-MaximiliansUniversität, Munich) for their input on the study design and in analysing and interpreting the mineral digestibility and hormone data.

This work was funded by Mars Petcare. The WALTHAM ${ }^{\circledR}$ Centre for Pet Nutrition is a fundamental research centre for Mars Petcare.

J. S., M. G., D. A. and P. J. M. conceived the project. J. S., P. W., M. G., J. A. and A. C. developed the overall research plan and had study oversight. J. S., M. G. and J. A. conducted the research. R. H. and A. C. performed the statistical analysis. J. S. and P. W. wrote the paper with M. G., D. A., J. A. and P. J. M.; P. W. had primary responsibility for the final content.

J. S., P. W., M. G., D. A., J. A., R. H., A. C. and P. J. M. are employees of Mars Petcare.

\section{References}

1. de Brito Galvao JF, Nagode LA, Schenck PA, et al. (2013) Calcitriol, calcidiol, parathyroid hormone, and fibroblast growth factor-23 interactions in chronic kidney disease. $J$ Vet Emerg Crit Care (San Antonio) 23, 134-162.

2. Bronner F (2003) Mechanisms of intestinal calcium absorption. J Cell Biochem 88, 387-393.

3. Nap RC \& Hazewinkel HAW (1994) Growth and skeletal development in the dog in relation to nutrition; a review. Vet $Q$ 16, 50-59.

4. Mack JK, Alexander LG, Morris PJ, et al. (2015) Demonstration of uniformity of calcium absorption in adult dogs and cats. J Anim Physiol Anim Nutr (Berl) 99, 801-809.

5. Schmitt S, Mack JK, Kienzle E, et al. (2013) No adaptation of apparent digestibility and fecal excretion to low calcium intake in adult dogs. Proceedings 17th European Society of Veterinary and Comparative Nutrition Congress, 19-22 September 2013, pp. 30.
6. National Research Council (US) (2006) Ad Hoc Committee on Dog and Cat Nutrition. Washington, DC: National Academies Press.

7. Dobenecker B, Kasbeitzer N, Flinspach S, et al. (2006) Calcium-excess causes subclinical changes of bone growth in Beagles but not in Foxhound-crossbred dogs, as measured in X-rays. J Anim Physiol Anim Nutr 90, 394-401.

8. Whiting SJ \& Wood RJ (1997) Adverse effects of high-calcium diets in humans. Nutr Rev 55, 1-9.

9. Institute of Medicine (2011) Dietary Reference Intakes for Calcium and Vitamin D. Washington, DC: National Academies Press.

10. American Association of Feed Control Officials (2016) American Association of Feed Control Officials Official Publication. Washington, DC: The Association of Feed Control Officials Inc.

11. German AJ, Holden SL, Moxham GL, et al. (2006) A simple, reliable tool for owners to assess the body condition of their dog or cat. J Nutr 136, 2031S-2033S.

12. Bexfield NH, Heiene R, Gerritsen RJ, et al. (2008) Glomerular filtration rate estimated by 3-sample plasma clearance of iohexol in 118 healthy dogs. $J$ Vet Intern Med 22, 66-73.

13. Wood RJ \& Zheng JJ (1997) High dietary calcium intakes reduce zinc absorption and balance in humans. Am J Clin Nutr 65, 1803-1809.

14. Gagné JW, Wakshlag JJ, Center SA, et al. (2013) Evaluation of calcium, phosphorus, and selected trace mineral status in commercially available dry foods formulated for dogs. $J \mathrm{Am}$ Vet Med Assoc 243, 658-666.

15. Bradshaw JWS (2006) The evolutionary basis for the feeding behavior of domestic dogs (Canis familiaris) and cats (Felis catus). J Nutr 136, 1927S-1931S.

16. Papakonstantinou E, Flatt WP, Huth PJ, et al. (2003) High dietary calcium reduces body fat content, digestibility of fat, and serum vitamin D in rats. Obes Res 11, 387-394.

17. Jacobsen R, Lorenzen JK, Toubro S, et al. (2005) Effect of short-term high dietary calcium intake on 24-h energy expenditure, fat oxidation, and fecal fat excretion. Int $J$ Obes (Lond) 29, 292-301.

18. Kienzle E, Dobenecker B, Wichert B, et al. (2006) Effect of fecal water and dry matter excretion on fecal mineral excretion in dogs studied in a fiber model. J Nutr 136, 2001S-2003S.

19. Hazewinkel HAW, Van den Brom WE, Van 'T Klooster AT, et al. (1991) Calcium metabolism in Great Dane dogs fed diets with various calcium and phosphorus levels. J Nutr 121, S99-S106.

20. Bao SF, Windisch W \& Kirchgessner M (1997) Calcium bioavailability of different organic and inorganic dietary Ca sources (citrate, lactate, acetate, oyster-shell, eggshell, $\beta$-tri-Ca phosphate). J Anim Phys Anim Nutr 78, 154-160.

21. Ling GV, Franti CE, Ruby AL, et al. (1998) Urolithiasis in dogs. II: breed prevalence, and interrelations of breed, sex, age, and mineral composition. Am J Vet Res 59, 630-642. 